\title{
Alveolar haemorrhage in a case of high altitude pulmonary oedema
}

\author{
Colin K Grissom, Kurt H Albertine, Mark R Elstad
}

\author{
Division of \\ Respiratory, Critical \\ Care, and \\ Occupational \\ Pulmonary Medicine, \\ Department of \\ Internal Medicine, \\ University of Utah \\ School of Medicine, \\ Salt Lake City, Utah, \\ USA \\ C K Grissom \\ K H Albertine \\ M R Elstad
}

Nora Eccles Harrison

Cardiovascular

Research and Training

Institute

C K Grissom

M R Elstad

\section{Department of \\ Pediatrics}

K H Albertine

Medicine Service, Veterans Affairs

Medical Center, Salt

Lake City, Utah 84112,

USA

M R Elstad

Pulmonary and

Critical Care Division

in the Department of

Internal Medicine,

LDS Hospital, Salt

Lake City, Utah 84143,

USA

C K Grissom

Correspondence to:

Dr C K Grissom, Pulmonary and Critical Care Division,

LDS Hospital, 325 8th

Avenue, Salt Lake City, Utah

84143, USA

Received 27 October 1997

Returned to author

13 January 1998

Revised manuscript received

16 March 1998

Accepted for publication

29 April 1998

\begin{abstract}
A case of high altitude pulmonary oedema (HAPE) in a climber who made a rapid ascent on Mt McKinley (Denali), Alaska is described. The bronchoalveolar lavage (BAL) fluid contained increased numbers of red blood cells and an abundance of haemosiderin laden macrophages consistent with alveolar haemorrhage. The timing of this finding indicates that alveolar haemorrhage began early during the ascent, well before the onset of symptoms. Although evidence of alveolar haemorrhage has been reported at necropsy in individuals dying of HAPE, previous reports have not shown the same abundance of haemosiderin laden macrophages in the BAL fluid. These findings suggest that alveolar haemorrhage is an early event in HAPE.
\end{abstract}

(Thorax 2000;55:167-169)

Keywords: alveolar haemorrhage; pulmonary oedema; altitude illness; acute respiratory distress syndrome (ARDS); high altitude

High altitude pulmonary oedema (HAPE) occurs in susceptible persons who ascend to altitudes above $2500 \mathrm{~m}$ and remain there for 24 hours or longer. " HAPE, a form of "noncardiogenic" or "increased permeability" pulmonary oedema, is associated with increased pulmonary artery pressure and normal pulmonary capillary wedge pressure. ${ }^{2}$ In two previous studies using bronchoscopy and bronchoalveolar lavage (BAL) in subjects with HAPE Schoene and colleagues reported an increased protein concentration, increased numbers of inflammatory cells, and increased concentrations of inflammatory mediators in alveolar oedema fluid. ${ }^{34}$ In one study BAL fluid contained increased numbers of red blood cells in three subjects with acute HAPE $\left(26.4 \times 10^{5}\right.$ cells $/ \mathrm{ml})$ compared with controls $\left(0.1 \times 10^{5}\right.$ cells $/ \mathrm{ml})^{4}$ and in the second study "occasional erythrophagocytic macrophages" were observed. ${ }^{3}$ This is consistent with the clinical observation in HAPE of a dry non-productive cough that progresses to a cough productive of pink frothy sputum due to blood-tinged alveolar oedema fluid. Studies of lungs at necropsy in persons dying of HAPE have shown an abundance of haemosiderin laden macro- phages and increased numbers of red blood cells in focal areas of alveolar haemorrhage. ${ }^{56}$ Haemosiderin laden macrophages are not observed until at least 48 hours after the onset of alveolar haemorrhage. ${ }^{78}$ Comparison of prior BAL studies of acute HAPE, where few haemosiderin laden macrophages were observed, with necropsy findings suggest that alveolar haemorrhage occurs coincident with or after the onset of symptoms in HAPE and numerous haemosiderin laden macrophages are not observed until later.

We now present the case of a climber on $\mathrm{Mt}$ McKinley (Denali), Alaska who developed a classic case of HAPE. BAL in the acute setting showed an abundance of haemosiderin laden macrophages consistent with alveolar haemorrhage that began during a strenuous climbing ascent before any clinical symptoms of HAPE appeared. This suggests that alveolar haemorrhage may occur early in the pathophysiology of HAPE.

\section{Case report}

A 28 year old male climber from Switzerland was previously healthy. On previous ascents up to $4800 \mathrm{~m}$ he had developed symptoms of acute mountain sickness but he had no history of HAPE. During the first day of an expedition to Denali he flew by plane from sea level to the $2100 \mathrm{~m}$ air landing strip on the Kahiltna glacier, arriving at midday, and then ascended to a camp at $2900 \mathrm{~m}$. On day 2 he ascended to the $4200 \mathrm{~m}$ camp where, on arrival, he was fatigued but had no symptoms of HAPE. That night he developed a non-productive cough and had difficulty sleeping. On day 3 he noted a marked decrease in exercise tolerance and an increase in his cough with production of frothy sputum. He presented to the National Park Service medical tent at $4200 \mathrm{~m}$ late on the third night of his expedition complaining of dyspnoea at rest, cough productive of pink frothy sputum, and inability to sleep. He had taken no medications for his symptoms. On physical examination he had a pulse of 111 $\mathrm{bpm}$, respiratory rate of 20 breaths $/ \mathrm{min}$, an arterial oxygen saturation $\left(\mathrm{SpO}_{2}\right)$ of $74 \%$ as measured by a digital pulse oximeter, central cyanosis, and bilateral inspiratory crackles on chest auscultation. Heart sounds and jugular venous pressure were normal. Treatment with supplemental oxygen delivered via nasal can- 


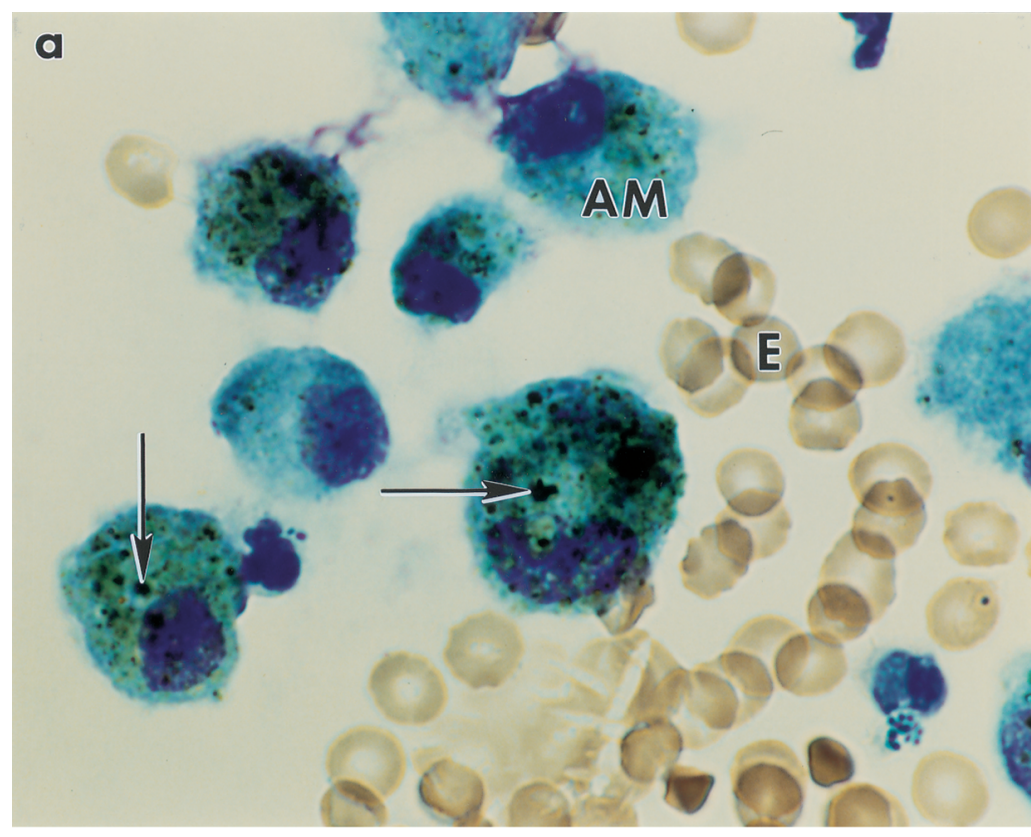

b

$10 \mu \mathrm{m}$

Figure 1 Increased red blood cells and haemosiderin laden macrophages in bronchoalveolar lavage fluid from a climber with high altitude pulmonary oedema.

(a) Giemsa stained smear of bronchoalveolar lavage sample from the subject who developed high altitude pulmonary oedema with alveolar haemorrhage showing large numbers of erythrocytes $(E)$ and numerous alveolar macrophages (AM) laden with haemosiderin inclusions (arrows) in the cytoplasm. (b) Smear of bronchoalveolar lavage fluid from a normal individual; the only cell type present are alveolar macrophages (AM) which lack haemosiderin inclusions. (a) and (b) are the same magnification.

nula at $2-31 / \mathrm{min}$ increased his $\mathrm{Spo}_{2}$ from $74 \%$ to more than $85 \%$ (normal $\mathrm{SpO}_{2}$ at $4200 \mathrm{~m}$ on Denali is $85 \%$ ).

The next morning (day 4) fibreoptic bronchoscopy and BAL were performed after obtaining informed consent. Inspection of the airways showed minimal pink secretions and no endobronchial lesions. BAL was performed in the lingula with return of $65 \mathrm{ml}$ of sanguineous lavage fluid after instillation of $150 \mathrm{ml}$ of sterile normal saline. The BAL specimen was immediately centrifuged, supernatant decanted, and cell pellet re-suspended. The total cell count was performed using a haemacytometer and the cell differential was determined on airdried slides stained with Giemsa. Total leucocyte cell count was $2.3 \times 10^{5}$ cells $/ \mathrm{ml}$, higher than the mean values of healthy asymptomatic altitude controls $\left(0.8(0.2) \times 10^{5}\right.$ cells $/ \mathrm{ml}, \mathrm{n}=$ $5)$. The leucocyte cell differential was normal (93\% macrophages, 4\% neutrophils, 3\% lymphocytes). Total protein was $258 \mathrm{mg} / \mathrm{dl}$, also higher than altitude controls (6 (3) $\mathrm{mg} / \mathrm{dl}, \mathrm{n}=$ 5). Total red blood cell count was $45 \times 10^{5}$ cells $/ \mathrm{ml}$ (controls $0.8(1.3) \times 10^{5}$ cells $/ \mathrm{ml}, \mathrm{n}=$ $5)$. The Giemsa stained slide smear was remarkable for numerous red blood cells and foamy haemosiderin laden macrophages (fig 1). Using the method described by Kahn and colleagues $^{9}$ the BAL haemosiderin score was 139 or, using an alternative scoring system, ${ }^{10}$ $73 \%$ of alveolar macrophages contained haemosiderin inclusions. These scores correlate with the highest category in either system, indicating a severe degree of alveolar haemorrhage. BAL fluid from altitude controls and two climbers with acute mountain sickness (data not reported) showed no haemosiderin laden macrophages.

After completion of the bronchoscopy and BAL the patient improved while on supplemental oxygen for another 24 hours. He then descended with his climbing partner on day 5 to $3400 \mathrm{~m}$ for one night, then to $3000 \mathrm{~m}$ for two nights. He experienced complete resolution of his symptoms and on day 8 from the start of his expedition he re-ascended to $4200 \mathrm{~m}$ without recurrence of HAPE. After re-acclimatisation at $4200 \mathrm{~m}$ he reached the summit of Denali at $6194 \mathrm{~m}$ on day 12, one week after presenting with HAPE. Since his return home from Denali he has remained healthy and active and continues to pursue mountaineering in the European Alps.

\section{Discussion}

Increased numbers of red blood cells in BAL fluid may be the result of haemorrhage, airway inflammation and bleeding in bronchitis or pneumonia, or trauma caused by the bronchoscope. Haemosiderin laden macrophages appear 48 hours after clinical alveolar haemorrhage $^{78}$ and 72 hours after cultured human alveolar macrophages are exposed to antibody coated sheep red blood cells. ${ }^{7}$ The BAL findings in the patient presented here are diagnostic of alveolar haemorrhage: increasingly sanguineous fluid on sequential lavage aspirations and numerous haemosiderin laden macrophages and red blood cells on microscopic examination.

Alveolar haemorrhage and haemosiderin laden macrophages are frequently associated with immune mediated alveolitis but may be seen in other types of lung injury. ${ }^{11}{ }^{12}$ For example, they have been reported in congestive heart failure, presumably secondary to rupture of capillaries caused by high pressure, ${ }^{13}$ and in the acute respiratory distress syndrome (ARDS) coincident with endothelial and epithelial cell injury which results in increased permeability pulmonary oedema. ${ }^{12}$ There was no clinical reason to suspect any cause for alveolar haemorrhage other than HAPE in our subject. His clinical course was not consistent with immune mediated alveolar haemorrhage or ARDS, but was consistent with HAPE 
which is characteristically an easily reversible form of increased permeability pulmonary oedema. Only one week after an episode of alveolar haemorrhage this climber had recovered sufficiently to reach the summit of the highest mountain in North America.

Schoene and colleagues did not report a similar degree of haemosiderin laden macrophages in BAL fluid from six climbers with HAPE also studied at $4200 \mathrm{~m}$ on Denali. ${ }^{34}$ There are several possible reasons for this discrepancy. Firstly, we used a different stain (Giemsa rather than Diff-Quik, Baxter Healthcare, McGaw Park, Illinois, USA) after fixing air dried slides in methanol which may have resulted in increased contrast of haemosiderin inclusions in macrophages. Schoene and colleagues do not report a fixation technique, which might decrease staining of haemosiderin inclusions. ${ }^{14}$ Secondly, we used a systematic scoring system that might have focused our observation toward haemosiderin laden macrophages. Thirdly, our subject had a faster rate of ascent, approximately 36 hours from $2100 \mathrm{~m}$ to $4200 \mathrm{~m}$ (and 48 hours from sea level). Schoene reported a 2-3 day ascent from $2100 \mathrm{~m}$ to $4200 \mathrm{~m}$ for subjects with HAPE. The very rapid strenuous ascent from sea level to $4200 \mathrm{~m}$ in our subject may have promoted a greater degree of alveolar haemorrhage due to increased pulmonary artery pressure and mechanical damage to pulmonary capillary endothelial cells.

The most novel finding in this case report is the abundance of haemosiderin laden macrophages in BAL fluid obtained during an acute presentation of HAPE. This indicates that bleeding in the lung probably began during a strenuous ascent from $2100 \mathrm{~m}$ to $4200 \mathrm{~m}$ before onset of symptoms. In association with increased pulmonary artery pressure in HAPE, Hultgren ${ }^{15}$ has proposed that uneven hypoxic pulmonary vasoconstriction results in overperfusion of some parts of the pulmonary vascular bed. Alveolar haemorrhage in our patient may therefore have been caused acutely by increased pulmonary artery pressure leading to overperfusion and rupture of the pulmonary capillary bed in selected areas. This is consistent with the hypothesised role for increased pressure leading to mechanical damage to pulmonary endothelial cells early in the pathogenesis of HAPE. Shear stress from increased velocity of blood flow may cause mechanical endothelial cell injury as proposed by Staub $^{13}$ or increased transmural pressure may cause stress failure of pulmonary capillaries as proposed by West et al. ${ }^{16}$ Alternatively, or concomitantly, an inflammatory reaction triggered by hypoxia or mechanical injury to endothelial cells may further increase vascular permeability.

The findings in this subject suggest that alveolar haemorrhage may occur early during rapid ascent to high altitude in HAPE. This is consistent with mechanical injury to pulmonary capillary endothelial cells.

The authors thank the staff of Denali National Park, the 210th Air Rescue Squadron, Kulis Air National Guard Base (Anchorage, Alaska), Morris Travel (Salt Lake City, Utah), and Olympus America Inc. Endoscope Division (Long Beach, California) for support of this project and Dr Guy A Zimmerman for helpful discussions.

This work was supported by awards from the Wilderness Medical Society, the Nora Eccles Treadwell Foundation, the Richard $A$ and Nora Eccles Harrison Fund for Cardiovascular Research, and by a National Institutes of Health Special Center of Research in ARDS (HL 50153).

1 Schoene RB, Hackett PH, Hornbein TF. High altitude. In Murray TF, Nadel JA, eds. Textbook of respiratory medicine. Philadelphia: WB Saunders, 1994: 2062-98.

2 Hultgren HN, Lopez CE, Lundberg E, et al. Physiologic studies of pulmonary edema at high altitude. Circulation 1964;29:393-408.

3 Schoene RB, Swenson ER, Pizzo CJ, et al. The lung at high altitude, bronchoalveolar lavage in acute mountain sicknes altitude, bronchoalveolar lavage in acute mountain sickne

4 Schoene RB, Hackett PH, Henderson WR, et al. High altitude pulmonary edema, characteristics of lung lavage fluid. ҰAMA 1986;256:63-9.

5 Dickinson J, Heath D, Gosney J, et al. Altitude-related deaths in seven trekkers in the Himalayas. Thorax 1983;38 646-56.

6 Hultgren HN, Wilson R, Kosek JC. Lung pathology in high altitude pulmonary edema. Wilderness and Environmental Med 1997;8:218-20.

7 Sherman JM, Winnie G, Thomassen MJ, et al. Time course of hemosiderin production and clearance by human pulmonary macrophages. Chest 1984;86:409-11.

pulmonary macrophages. Chest 1984;86:409-11.
8 Grebski E, Hess T, Hold G, et al. Diagnostic value of hemosiderin-containing macrophages in bronchoalveolar hemosiderin-containing macrop
lavage. Chest 1992;102:1794-9.

9 Kahn FW, Jones JM, England KM. Diagnosis of pulmonary hemorrhage in the immunocompromised host. Am Rev Respir Dis 1987;136:155-60.

10 de Lassence A, Fleury-Feith J, Escudier E, et al. Alveolar hemorrhage, diagnostic criteria and results in $194 \mathrm{immu}-$ nocompromised hosts. Am f Respir Crit Care Med 1995;151:157-63.

11 Leatherman JW, Davies SF, Hoidal JR. Alveolar hemorrhage syndromes, diffuse microvascular lung hemorrhage in immune and idiopathic disorders. Medicine 1984;63:34361 .

12 Schwarz MI, Cherniack RM, King TE. Diffuse alveolar hemorrhage and other rare infiltrative disorders. In: Murray TF, Nadel JA, eds. Textbook of respiratory medicine. Murray TF, Nadel JA, eds. Textbook of respirator
Philadelphia: WB Saunders, 1994: 1889-12.

13 Staub NC. Pulmonary edema due to increased microvascular permeability to fluid and protein. Circ Res 1978;43:14351

14 Lillie RD, Fullmer HM. Histopathologic technic and practical histochemistry. 4th ed. New York: McGraw-Hill, 1976: 501-8.

15 Hultgren HN. High altitude pulmonary edema. In: Staub $\mathrm{N}$, ed. Lung water and solute exchange. New York: Marcel Dekker, 1978: 437-69.

16 West JB, Colice GL, Lee YJ, et al. Pathogenesis of high altitude pulmonary oedema: direct evidence of stress failure of pulmonary capillaries. Eur Respir f 1995;8:523-9. 